\title{
MESA REDONDA: CONDIÇÕES PRESENTES DA CRÍTICA DE ARTE
}

Mediação: Fabíola Tasca

RESUMO: O título deste texto emula o daquele publicado na Revista October, em 2002-Rounde Table: The Present Conditions of Art Criticism - que reúne a conversação presencialmente acontecida entre nomes proeminentes do espaço teórico e crítico norte-americano. Aqui lanço mão da ideia original de Jorge Menna Barreto em sua dissertação de mestrado, Lugares Moles, na qual ele produz uma conversa imaginária entre diversos atores do mundo da arte, discutindo questões relativas ao sitespecificity, a partir de excertos de determinados textos.

Na Mesa Redonda aqui apresentada, reúno fragmentos discursivos de alguns críticos, principalmente de agentes do espaço teórico e crítico brasileiro. Assim como Menna Barreto adverte, as falas contidas neste *fabiolabh@gmail.com

Artista, pesquisadora e professora na Universidade do Estado de Minas Gerais - Unidade Escola Guignard. Doutora em Artes pela Escola de Belas Artes da UFMG.

texto são apropriações para um uso específico, tratandose de uma versão livre e experimental; portanto não devem ser utilizadas como citações. Para tanto, devese recorrer à bibliografia original listada no final deste texto.

PALAVRAS-CHAVE: Crítica de arte; mediação; arte contemporânea; arte e contemporaneidade; leituras contemporâneas. 
Mediadora - O título dessa mesa aponta para a intenção de delinearmos algumas balizas da crítica de arte na atualidade; mais especificamente estamos aqui reunidos para tentar compreender quais desafios e questões a arte contemporânea coloca para o exercício da crítica. Assim, para falarmos nas condições presentes da crítica de arte, poderíamos começar situando o termo "contemporâneo"..

Ronaldo Brito - Eu vejo pelo menos três modalidades de contemporaneidade. Uma é a contemporaneidade universa do historiador de arte e do crítico em relação ao seu objeto. Não importa a datação do objeto, o que define a história da arte é exatamente a contemporaneidade do objeto - ele estar na sua frente. Tudo começa no corpo a corpo com a obra. Essa contemporaneidade, o fato de você aceitar o instante da obra e conseguir fazer o instante da obra também, recriá-la no instante crítico, é fundamental. Isso é muito amplo e vale em todos os sentidos. Então, essa primeira é uma contemporaneidade, digamos, universal.

A segunda contemporaneidade é muito mais particularizada e diz respeito ao que eu entendo como uma atividade crítica contemporânea, que é a do acompanhamento, que inclui obviamente $o$ aspecto indicativo e $o$ aspecto valorativo, mas que - talvez pela minha formação mais romântica -, consiste na recriação crítica do trabalho, na recriação poética do trabalho. Eu tendo a praticar uma crítica contemporânea no sentido em que eu vejo muito mais o vir a ser da obra, procuro ingressar no universo poético do artista, aderir a isso. Isso valia tanto para a minha relação com Iberê Camargo, ou com Sérgio Camargo, ou com Amílcar de Castro, Eduardo Sued, para não falar dos artistas da minha geração, Waltercio, Tunga, e outros, e também para os artistas mais jovens - eu acabo, por exemplo, de escrever um texto sobre a Gabriela Machado. Isso significa uma espécie de vetor da crítica de arte, que é uma crítica que trabalha com uma parceria com o artista. Não tanto com o artista, mas com a obra, com o processamento da obra, com o vir a ser da obra. E, nesse sentido, eu faço duas caracterizações, poderiam ser mais, mas são duas, para o crítico de arte contemporâneo perceber que, nesse tipo de envolvimento crítico, a relação do artista com a obra é crucial. Para o crítico existe não só a obra, mas a relação do artista com a obra. Isso é inevitável e não é algo que eu considere pessoal, é algo que eu considero um fenômeno poético. Eu nunca encontrei, a não ser com uma ou outra exceção, um bom artista que não tenha uma bonita relação com a sua obra. Encontrei já um ou dois artistas com uma relação feia com a sua obra, com uma relação venal com a sua obra ou uma relação falseada com a sua obra. Mas, no geral, a integridade da relação do artista com a sua obra é crucial. E, por integridade, eu também digo a intensidade e tudo mais. Isso faz parte do processo contemporâneo, eu não vejo como,
EM TESE
BELO HORIZONTE
v. 19
N. 1
JAN.-ABR. 2013
TASCA. Mesa redonda: Condições presentes da crítica de arte
P. $192-207$

\section{Crítica Literária, outras Artes e Midias}


para esse gênero de crítica, você se subtrair a isso, porque aî sim, seria falsear, aí sim talvez essa crítica, paradoxalmente, permita um envolvimento, ou antes, um ajuizamento meno parcial, mais imparcial, porque você passa a compreender o processo de dentro, do fundamento dele. E a outra observação que eu faço, também de caráter, digamos, talvez, empírico, é que o crítico deve perceber que o trabalho novo transforma o trabalho antigo, altera o trabalho antigo, já que não existem trabalhos em si, só existem trabalhos lidos, trabalhos criticados. Eu percebi, é um mistério, porque evidentemente os trabalhos não se transformam materialmente, mas eles se apresentam em uma nova luz; à medida que os trabalhos vão surgindo, eles vão criando novas leituras e vão se transformando, vão se alterando. É um fenômeno curioso, poético, talvez da própria pulsação da vida humana, da indeterminação da percepção humana, de como o trabalho novo vai modificando o antigo. Isso é um alerta para compreender como isso tudo é um processo em aberto, e as certezas ali são sempre as certezas incertas, indeterminadas.

O terceiro aspecto da contemporaneidade, mais amplo, é que evidentemente não se pode fazer uma sinonímia entre o contemporâneo e o atual no sentido empírico, corrente. Então, seja de que maneira a gente esteja usando o termo contemporâneo, ele envolve uma conceituação, envolve uma valoração e uma conceituação. Essa conceituação de contemporâneo, quando eu comecei no meio dos anos 1970, mais ou menos, isso não era discutível. Ou seja, contemporâneo era sinônimo de experimental. E, experimental era sinônimo de forçar o limite do suporte, forçar o limite histórico da modernidade. Evidentemente, isso não se sustentou ao longo do tempo, a questão se revelou muito mais complexa, muito mais ambígua, muito mais viscosa, muito mais problemática. E, o que eu continuo a sustentar como contemporaneidade é uma modernidade modificada, que por um lado reafirma aquele princípio da autonomia da arte moderna, autonomia claro sempre problemática, sempre conflituosa, mas autonomia da livre pesquisa do saber, livre pesquisa da linguagem. E, por outro lado, evidentemente, não pode mais trabalhar naquele regime da pureza ideal da modernidade, seja pureza ideal da arte, seja pureza ideal também da anti-arte - porque também essa arte transgressiva, todo o aspecto Dadá e duchampiano, também participava desse clima, pós-iluminista e romântico, também esperava o gênero negativo, mas um resultado social, cultural. Então, do meu ponto de vista, hoje é impossível, tanto uma arte formalista, ideal, como uma anti-arte transgressiva, que é o lado da sombra da arte. Eu acho que, hoje em dia, cada um deve enfrentar essa questão por si, mas de uma maneira geral, tendo a opor uma noção de contemporâneo, como uma modernidade modificada, modernidade recriticada, com essa diluição da arte em

\section{Crítica Literária, outras Artes e Midias}


cultura, essa diluição da arte em comunicacão social, que é praticada pela maioria dos pós-modernos. (1)

Mediadora - um aspecto saliente da contemporaneidade é a diluição das categorias tradicionais; se até o início do século $\mathrm{XX}$, categorias tais como pintura e escultura apresentavam contornos algo precisos e os territórios revelavam jurisdições menos ambíguas, a própria categoria "obra de arte" foi sendo esgarçada pela ação das vanguardas ...

Agnaldo Farias - Sim, eu não creio que estas categorias sirvam mais. Estilo também é uma categoria que pertence a outra concepção de arte, ela tem a ver com o desenvolvimento de uma singularidade de fala, de um vocabulário formal e uma maneira de conduzir este vocabulário, a recorrência a determinadas soluções formais. Em qual estilo você vai enquadrar a obra de um sujeito como o Mark Dion que estava na $26^{\circ}$ Bienal de São Paulo? Não existe isso. O que existe é a recorrência de alguns procedimentos, o denominador comum de alguns raciocínios. São incontáveis os artistas que utilizam os mais variados suportes. Você pode pensar em estilo quando está diante de um Iberê Camargo. Mas, hoje em dia, para artistas como Nuno Ramos, Vera Chaves Barcelos, Cildo Meireles, Karin Lambrecht, Daniel Acosta, Elida Tessler, esta questão não está colocada. Eu não acho que existam tendências, como também não existe mais essa idéia de vanguarda. Do mesmo modo o termo tendência é demasiado genérico e termina por encobrir singularidades. E, se você for ver, mesmo as tais tendências históricas como por exemplo, o Expressionismo Abstrato, sucumbem quando você as examina de perto.

Então, o que é intrínseco à arte contemporânea é justamente a convivência dessa pluralidade, essa ruptura com as categorias convencionais, esse não lugar. É esse consórcio, agenciamento, transpassamento de disciplinas; trabalhos que discutem com a filosofia, com a política, com a sociologia, com a medicina, com as mais variadas formas de conhecimento e de práticas. Quando no final dos anos 50, Mário Pedrosa falou da arte pós-moderna, o que ele estava querendo dizer era exatamente isso: existe um tipo de produção hoje, que não se coloca mais como nem pintura, nem escultura, nem desenho, nem gravura. Quando Barnett Newman ao explicar, de uma maneira irônica, o que era escultura - "é tudo aquilo que você esbarra quando você se afasta para ver uma pintura" - ele está querendo dizer também que a categoria escultura não funciona mais. (2)

Cristina Freire - Sim, termos e categorias disponíveis até então como pintura, escultura, desenho e gravura não dão mais conta do universo de proposições dos artistas contemporâneos. Novos termos são acrescentados às definições sempre cambiantes. A existência objetual da obra de arte volatiliza-se e a figura do artista isolado também se torna

\section{Crítica Literária, outras Artes e Mídias}


problemática. $\mathrm{O}$ objeto artístico não mais ocupa o centro da cena. A negação da objetividade material (e do destino mercadológico) como atributo da obra de arte se dá em favor de ações e eventos transitórios no tempo e instáveis no espaço. Nesse momento atual, que Arthur Danto chama de pós-histórico, a crítica de arte deve ser necessariamente pluralista, uma vez que não há formas únicas, diferentemente da Era dos Manifestos quando a crítica é excludente. Tudo isso sinaliza o fim das narrativas hegemônicas e arte deixa de ser uma disciplina exclusivamente relacionada à História e uma afasia lingüística domina o discurso crítico. (3)

Mediadora - Vocês percebem algum problema para a crítica de arte diante desse panorama que Cristina menciona? Pergunto isso porque tenho a impressão que Hal Foster aponta o pluralismo como uma ameaça para a tarefa crítica, enquanto Arthur Danto parece ter uma posição menos "pessimista".

Arthur Danto - Bom, a Era Moderna definiu uma forma de crítica em contraposição à qual estou ansioso por definir a minha própria. O que eu pretendo assinalar com a reivindicação de que a arte chegou a um fim é dizer que as críticas excludentes não são mais legítimas. Nenhuma arte é mais historicamente imperativa comparada com qualquer arte. Nenhuma arte é historicamente mais verdadeira do que outra, nem em especial mais falsa. Assim, no mínimo, a crença de que a arte chegou a um fim exige um tipo de crítico que não se pode ser, se alguém pretende ser crítico de qualquer modo: não pode mais haver nenhuma forma de arte determinada historicamente, todo o resto sendo colocado além dos limites. (4)

Hal Foster - Este é um ponto importante. A arte existe hoje num estado de pluralismo: nenhum estilo ou mesmo modo de arte se mostra dominante, e nenhuma posição crítica é ortodoxa. Mas, eu acho que só se pode começar por um descontentamento com esse status quo: pois num estado pluralista a arte e a crítica tendem a se dispersar e, portanto, a se tornar impotentes. Como designação, pluralismo não significa nenhum tipo de arte especificamente. Ou melhor, é uma situação que concede uma espécie de equivalência; arte de várias espécies passa a parecer mais ou menos igual - igualmente (des)importante. Tida como liberdade a ser escolhida, a posição pluralista faz parte da ideologia do "livre mercado". (5)

Teixeira Coelho - A questão está colocada nos seguintes termos: se o pluralismo é a tônica atual das artes visuais, a única coisa que a crítica parece poder fazer é apreciar cada obra em si mesma e por si mesma, nos termos de suas premissas e referências e segundo suas proposições - de tal forma que de fato nada haveria a ser dito preliminarmente sobre os critérios da crítica. É a atitude que Artur Danto
EM TESE
BELO HORIZONTE
v. 19
N. 1
JAN.-ABR. 2013
TASCA. Mesa redonda: Condições presentes da crítica de arte
P. $192-207$

\section{Crítica Literária, outras Artes e Mídias}


defende, por exemplo. Quando não há mais narrativas prévias que justifiquem a obra de arte - a narrativa do realismo socialista ou da inclusão social ou dos princípios básicos da ótica como vetor da pintura ou a narrativa da ascendência do subconsciente sobre a criação artística ou a do privilégio da forma geométrica sobre qualquer outra - e realmente não as há mais, e, felizmente, não as há mais, a saída seria enfrentar cada obra de peito aberto e, portanto, nunca explicitar de antemão, nem mesmo a posteriori, os princípios que orientariam e orientaram a crítica. Se tudo vale para o artista, tudo vale para o crítico. E para o curador.

Nesse sentido, como observa o escritor Milan Kundera, todo juízo estético tende a apresentar-se como uma aposta pessoal - do artista, do escritor, do crítico. O problema é que essa aposta não se esgota numa pura subjetividade: ela enfrenta outros juízos, quer ser reconhecida de fora, aspira a alguma objetividade ou aspira em todo caso a uma inter ou trans-subjetividade, não se contenta com manter apenas uma validade interna, restrita ao âmbito de quem a formula do interesse apenas de seu formulador. Então, a pergunta é: onde buscar condição para alcançar essa ampliação do gosto subjetivo? A primeira resposta cabível é que essa trans-subjetividade se procura e se encontra na história. Dito de outro modo, os valores que posso adotar como guia de minhas preferências, de meu gosto, e que, portanto não é mais apenas meu gosto, mas, um gosto que aspira a alguma comunidade, situam-se na história da arte sob estudo. (6)

Agnaldo Farias - Acontece que no momento que você tinha só quatro modalidades hegemônicas de suporte artístico - pintura, escultura, desenho e gravura -, você tinha parâmetros dados pela própria história daqueles suportes. Por mais que eles fossem expandidos, fosse para lá, fosse para cá, você ainda encontrava certas recorrências, você tinha padrões comparativos. Hoje a coisa não se coloca tanto assim. Hoje, tem um experimentalismo muito grande, ficou mais difícil de você se situar, até porque o território da arte envolve referências, conhecimentos, tecnologia, questões que são muito variadas, e o público tem que lidar com essas coisas É freqüente que o público não saiba como lidar com ela. É natural que ele não saiba por onde pegar, até porque não tem um referencial, não tem um repertório para isso. Então, eu acho que tem um dado complicador. Mas, isso não quer dizer que não existam critérios, ou que não se possa dizer de um trabalho que ele tenha maior ou menor qualidade. Acho que é possível sim, trabalhos com mais potência poética, trabalhos mais inquietantes, trabalhos dos quais minam mais significados, que deixam brotar maiores cargas de significação, maiores potências nesse sentido. Existe e sempre existirá obra mais inteligente, com maior grau de consistência. Todo jogo tem uma regra, todo conhecimento tem regras,

\section{Crítica Literária, outras Artes e Mídias}


cabe a você percebê-las e também perceber se estão aparafusadas, se estão justas, coesas. É esse o caminho. Como você consegue entrar na ordem e perceber ali alguma ordenação? É difícil, mas há de se fazer isso; esse continua sendo o papel do crítico, do curador, do professor. (7)

Mediadora - Falamos, então, de crise? Se a relação entre "Crítica" e "Crise" é fundadora do próprio campo da crítica de arte, tenho a impressão de que quando falamos em crise da crítica na atualidade falamos de certo enfraquecimento da tarefa e do exercício da crítica, enfraquecimento esse pontuado por Hal Foster como consequência de um estado pluralista. Declarações recorrentes tais como: "não há mais crítica de arte" ou, então, reclamações nostálgicas dirigidas ao contexto nacional: "como era boa a época de Mário Pedrosa!" são sintomas de quais condições presentes da crítica de arte?

Hal Foster - Entendo a tarefa da crítica como estreitamente relacionada à ideia de crise. Para mim a tarefa da crítica não é fundamentalmente julgar seu objeto esteticamente de acordo com um gosto mais ou menos subjetivo ou com uma norma conservadora, ou avaliá-lo em nome de uma probidade (honradez) ideológica de acordo com uma agenda política mais ou menos pré-determinada; nem é, como na hermenêutica humanista, completar ou animar o objeto por meio de sua interpretação (como se ele fosse deficiente ou estivesse morto) ou à maneira estruturalista re(constituí-lo) num simulacro crítico que esclareceria sua lógica. Ao invés disso, a crítica para mim segue junto com seu objeto numa investigação a respeito de seu próprio lugar e função como prática cultural em articulação com outras representações psicossociais: ao fazê-lo procura separar essas práticas criticamente e conectá-las discursivamente para conduzi-las à crise (que afinal de contas é o que a crítica significa) bem como para transformá-la”. (8)

Mediadora - Entendo que você vê a tarefa da crítica menos como juízo de gosto ou como interpretação e mais como uma prática de problematização que, ao mesmo tempo em que é feita, se interroga acerca de seu próprio lugar e função como prática cultural. Em seu livro Recodificação você assinala que diante da crise da crítica e de sua função social, o crítico deveria fazer uso dessa crise pra falar "precisa e impertinentemente fora de lugar"... um ponto que percebo como recorrente em muitos dos textos de alguns de vocês, consiste em salientar que a crítica de arte na atualidade expressa uma recusa em julgar.

Annateresa Fabris - Sim, isto é um sintoma importante. A mutação da natureza da arte nas últimas décadas colocou a crítica diante da necessidade de utilizar novos instrumentos teóricos e linguísticos, deixando de lado os juízos de valor que fundamentavam as leituras da modernidade, assumindo como modelo tanto a descrição quanto uma prosa poética 
e voluntariamente hermética, buscando justificativas não mais na artisticidade do objeto, mas num campo teórico cada vez mais vasto e diferenciado. A crítica contemporânea parece pautar-se, em linhas gerais, por uma síndrome que Migliorini denomina 'recusa a julgar'. Compreensível, de um lado, uma vez que hoje em dia as antigas escalas de valores não tem mais razão de ser, tal atitude não deixa, de outro, de evidenciar uma renúncia: atribuir uma objetividade de valor a uma 'obra de arte'. Confrontada com as manifestações contemporâneas, a crítica prefere ater-se a uma descrição aparentemente neutra e realizar apenas operações taxonômicas e metodológicas: organizar em categorias, dar títulos, classificar, por vezes motivar. (9)

Teixeira Coelho - Concordo com Annateresa e percebo um enfraquecimento da crítica em função desta recusa em julgar. Se compreender, apenas, for o modo de ser do "crítico", todos os atos unitários (as obras de arte em si) demonstram-se como "fatos da natureza", que não pedem e não aceitam nenhuma intervenção do juízo: são fatos que existem apenas para serem aceitos. Nessa linha de reflexão, um evento qualquer, tanto quanto uma obra de arte, nunca teria nada que não fosse pacífico e por si mesmo admissível: nada nele seria contraditório em relação a alguma coisa (ou em relação a si mesmo) e nada dele seria em si passível de ser contrariado: tal como um relâmpago ou um trovão, que não é contraditório a nada e que não pode ser contrariado." Estaríamos no território do relativismo e nenhuma critica seria possível, apenas a descrição - ou a elegia, e hoje a descrição já é uma elegia. (10)

Luis Camilo Osório - Muito tem sido dito sobre a crise da crítica. Com a diluição dos jornais e a pouca reverberação da produção universitária, é razoável que se tema pelo seu futuro. Esse recuo está relacionado à pulverização do público e ao sentimento de total desabrigo e desorientação diante da arte contemporânea. Pressionada entre a desinformação generalizada e o isolamento provocado pela linguagem especializada, a crítica parece ter perdido o território comum da discussão pública - determinante para o seu nascimento.

No fundo, o que tem que ser observado é que há uma relação direta entre a crise da crítica e a da política, ambas atividades voltadas para o debate, para a pluralidade de vozes e o vir a ser indefinido da arte e do mundo, cabendo a nós reinventarmos os seus espaços e formas de atuação. Acho que há que se pensar a crítica deslocando-a da posição de juiz (maneira tradicional de ver o crítico) para a de testemunha, que deve estar atenta aos fatos pra poder trazê-los a público. Por isso, não nutro nenhuma nostalgia pelo passado. Reconhecer a crise e as hesitações de nossa época tem como objetivo estar à altura dos desafios do presente. (11)

\section{Crítica Literária, outras Artes e Mídias}


Mediadora - Creio que tocamos no ponto: reconhecer a crise, mas não assumir uma postura nostálgica; recordo-me agora de uma advertência que sinaliza que a nostalgia é péssima conselheira, já que dita um compreensão do mundo pela falha e pela falta.

Luiz Camilo Osório - Para não embarcarmos numa atitude nostálgica convém salientar que é função primordia da crítica procurar compreender as transformações da arte, seus novos processos e materializações. Se a arte tem mudado radicalmente, desde pelo menos a década de 1960, seja do ponto de vista dos procedimentos, seja das expectativas de recepção, é fundamental que a crítica também se ponha em questão, redefina seus métodos, interesses e formas de disseminação pública. Então, na mesma medida em que é evidente o encolhimento da crítica jornalística nas últimas décadas, penso que algumas perguntas devem ser colocadas: A redução de espaço é um problema exclusivo da crítica? Por que concentrar sua discussão na perda de um veículo? Que outras formas de circulação, para além dos jornais, ganhou a reflexão sobre arte? A presença freqüente dos artistas nas universidades não seria uma aproximação da criação à crítica e não um afastamento? Atuando em jornal e na universidade, sinto que essa discussão não pode ser deixada de lado em nome de uma nostalgia estéril. (12)

EM TESE
BELO HORIZONTE

v. 19

\section{Crítica Literária, outras Artes e Mídias}


nas entrevistas com os atores, nas matérias sobre como foi a filmagem, etc., enquanto a "voz da crítica", o espaço dos ranzinzas, fica segregado em um quadrinho. Assim, pouco importa se o filme é uma bobagem ou não, o fato é que vai ser sucesso de temporada, então, "noticiamos". Na verdade, não estamos só noticiando, estamos desde o inicio supostamente consagrando o filme como sucesso da temporada Surge, então, outra distorção: supostamente estávamos dando esse destaque todo porque é do "interesse do público". Porém, terminamos atendendo, na verdade ao interesse do mercado. É o que parece estar acontecendo em geral com a linguagem dos nossos tempos: não se fala mais no que é bom para a sociedade, só se fala no que é bom para o mercado; não há mais cidadãos, classes, países, só o Mercado, com M maiúsculo. (13)

Mediadora - Luiz Renato Martins faz algumas considerações a esse respeito em uma entrevista para a revista Número. Renato, você poderia retomar alguns pontos daquela entrevista, salientando como você percebe essa ingerência do mercado na produção artística contemporânea?

Luiz Renato Martins - Bom, alguma coisa que caracteriza o corte do que eu chamaria de época moderna, em relação ao Antigo Regime, é que ela está fundada na liberdade. O que quer dizer isso? Liberdade é o artista ser capaz de escolher os seus materiais, os seus procedimentos, os seus temas, independente de qualquer academia, de qualquer poder da igreja ou independente do poder real. Os artistas produziam fundados na liberdade e depois, isso vinha para o mercado. Uma coisa que é diferente nos dias de hoje é que a chamada arte não é mais fundada na liberdade, mas no mercado. Ela é produzida a partir do mercado. Aquela esperança de que um trabalho, por ser produzido num outro campo que não o do museu, tivesse uma determinada eficácia crítica não tem mais cabimento. Todos os espaços estão administrados. A rua também faz parte do mesmo espaço que o museu faz, que é o espaço do mercado. Tudo é mercado hoje em dia. O problema é que a situação está criada de uma tal maneira que em todos os campos não existe mais reflexão e a arte era fundamentalmente reflexiva desde que ela estava fundada na liberdade. Por isso, eu não vejo que exista crítica de arte hoje em dia. Isso é um espaço que desapareceu, não tem mais espaço social para isso. O que você tem naquele espaço em que antigamente se exercia a crítica, que são as páginas dos jornais é uma cultura de release. Atualmente a permissividade é total. A grade do texto serve para marcar a individualidade do rapaz ou da moça em meio a uma multidão de outros. São protocolos de venda de produtos. E os trabalhos, as polêmicas, os debates, as pesquisas, estão no escuro total, prontos para serem descobertos. (14)
EM TESE
BELO HORIZONTE
v. 19
N. 1
JAN.-ABR. 2013
TASCA. Mesa redonda: Condições presentes da crítica de arte
P. $192-207$

\section{Crítica Literária, outras Artes e Mídias}


Mediadora - Os catálogos de exposições constituem um espaço proeminente para a presença dos textos críticos. Como vocês veem a possibilidade de exercer uma escrita fundamentalmente crítica no contexto dos catálogos?

Rodrigo Naves - Eu basicamente espalhei que parei de fazer crítica de catálogo. Eu acho que é um espaço muito bom pra quem está começando aprender a fazer análise de trabalhos, descrição e tal. Acho que esse espaço para mim foi ficando desinteressante, porque dificilmente você pode criticar alguém num texto de catálogo. Foi ficando desagradável, queriam de mim apenas o endosso. Como também se ganha muito pouco dinheiro com isso e como hoje em dia eu não preciso desse dinheiro porque vivo das minhas aulas, eu quis me livrar desse fardo. Então eu não faço mais nenhum. (15)

Mediadora - Você fala numa demanda por um texto que se posicione apenas como endosso, o que seria, claro, um esvaziamento da tarefa da crítica. E aqui voltamos se não à questão da recusa em julgar, à questão de uma impossibilidade de julgar em função de um cerceamento da atividade crítica. Ronaldo Brito, em um texto de 1975 , já apontava para a relação estreita entre certos textos críticos e a demanda do mercado.
Ronaldo Brito - Sim, neste texto eu procurava analisar algumas manobras do mercado porque a ação do mercado está longe de se restringir às transações financeiras. Ele age de modo a criar um sistema fechado dentro do qual o trabalho vai obrigatoriamente circular, desde sua própria concepção até a venda. É ingênuo supor que a ideologia do mercado se reduza a uma questão financeira e que todo o seu jogo seja descobrir o que é vendável e o que não é. O problema do mercado é, em última análise, conquistar um público de formação estranha à história da arte e que procura nela um investimento seguro e/ou signos de distinção de classe. Num certo nível, o discurso da arte funciona como um nítido processo de discriminação social. No caso do mercado brasileiro, que era o foco de minha atenção neste texto, seu objetivo é manter intacto o secular estatuto da arte no mundo ocidental: A arte como manifestação suprema e eterna (leia-se apolítica) da civilização cristã ocidental; a arte como manifestação reservada a alguns poucos eleitos, inteligentes e sensíveis, e que o são por dom, não por educação e aprendizado social; a arte como espaço mítico, fechado sobre si mesmo, uma espécie de moderno substituto da religião. A tarefa de vender arte prende-se obrigatoriamente à tarefa de defender o estatuto vigente da arte na sociedade - afinal é esse estatuto que assegura em última instância a possibilidade do comércio da arte. Daí a necessidade do mercado de

\section{Crítica Literária, outras Artes e Mídias}


elaborar uma estratégia que, sobre cada aspecto específico do circuito, atue de modo pertinente.

Assim, controlar a produção significa não apenas privilegiar e recalcar linguagens, mas divulgá-las de uma certa maneira, num espaço que porta significações prévias, convencionais, neutralizadoras do efeito crítico de algumas propostas. Controlar a fruição também é possível, uma vez que ao vender trabalhos o mercado vende não apenas o objeto mas uma determinada leitura dele. Nesse contexto, certo textos críticos funcionam como esotéricos apoios publicitários às obras. No caso o esoterismo é imprescindível: trata-se de manter a arte no terreno do ininteligível, do sublime, do não-discursivo. O 'mundo à parte', enfim. Quando não são vagas divagações metafísicas, esses textos se posicionam de um modo mítico em relação à arte, afastando assim os profanos. A função objetiva desses textos não é produzir conhecimento, nem sequer situar os trabalhos no ambiente cultural. Estão ali para superpor mais um nível ao discurso que vai envolver o produto e torná-lo, num primeiro momento, e, em seguida, objeto de prazer e consumo. (16)

Mediadora - Então, o desafio continua sendo, como você pontua em seu texto, promover uma fruição menos classista e mais inteligente dos trabalhos.
Ronaldo Brito - Sim, um interesse unânime dos artistas contemporâneos é que seus produtos sejam consumidos como fatos culturais, polarizadores de debates e leituras críticas. É óbvio que o simples ingresso de seus trabalhos no mercado - fato afinal desejável - não implica a obtenção desse nível de fruição. O mercado significa apenas e precisamente, em termos de produção, a garantia econômica da continuidade do trabalho. Independentemente de suas linguagens, passou a ser necessária aos artistas contemporâneos a manipulação de uma consciência estratégica que permita combater o incessante processo de recuperação e bloqueio de seus trabalhos. Talvez, mais do que isso, passou a ser necessário agir criticamente acerca da própria posição da arte na sociedade. Não basta a produção de linguagens contemporâneas e preciso produzir leituras contemporâneas. (17)

Mediadora - se pensamos no lugar do artista no contexto das universidades parece que tangenciamos certa possibilidade de se produzir tais leituras, bem como testemunhamos um deslocamento do artista através de funções que ultrapassam sua posição exclusiva como produtor de obras de arte.

Ronaldo Brito - Convém pontuar que se é impossível modificar a ideologia do mercado é sempre possível intervir criticamente na ideologia do circuito em seu conjunto. A partir do raciocínio que entende o circuito como um sistema com suas regras próprias - e que se pretende isolado, quase

\section{Crítica Literária, outras Artes e Mídias}


mítico - considero que só uma ação contínua tem alguma chance de transformá-lo. Não há dúvida, porém, que esse tipo de ação exige entre outras coisas que o artista, digamos, deixe de ser artista: livre-se do mito de 'ser criador' - posição que lhe assegura uma situação confortável, mas inútil - e pense em si mesmo como alguém que está amplamente comprometido com os sistemas e processos de significação em curso na sociedade. Por exemplo, neste texto de 75 eu apontava como uma estratégia interessante a tentativa de atrair para a audiência da arte contemporânea um público de estudantes. A criação de formas paralelas de divulgação e aproximação (em universidades e espaços públicos) com pessoas de fora do circuito me parecia naquele momento, $\mathrm{e}$ ainda hoje, uma estratégia importante. (18)

Ricardo Basbaum - Se falamos nesse trânsito do artista através de funções outras, que não a de exclusivo produtor de obras de arte, como uma característica distintiva do espaço contemporâneo, seria interessante comentar algumas impressões de tais estratégias de superposição de papéis a partir da experiência da invenção e produção de exposições - o campo das ações identificadas como 'curadoria'... (19)

\section{PARTICIPANTES}

Agnaldo Farias é professor da Faculdade de Arquitetura e Urbanismo da Universidade de São Paulo, crítico de arte e curador. Foi curador da 29a Bienal de São Paulo, juntamente com Moacir dos Anjos (2010), curador da Representação Brasileira da 25a. Bienal de São Paulo (1992), curador adjunto da 23a. Bienal de São Paulo (1996) e da 1a. Bienal de Johannesburgo (1995).

Annatreresa Fabris é historiadora e crítica de arte. Professora do Programa de Pós-graduação em Artes da Universidade de São Paulo. Pesquisadora do CNPq. Foi curadora de diversas exposições, É autora de vários livros dedicados à arte moderna, ao ecletismo e à fotografia.

Arthur Coleman Danto é professor emérito do Departamento de Filosofia da Universidade de Columbia, em Nova York. Tem inúmeros títulos publicados nas áreas de filosofia, estética e crítica de arte. Desde 1984 é crítico de arte da Revista The Nation, além de colaborar com outras publicações, como a Revista Artforum.

Cristina Freire é mestre em administração de museus e galerias de arte pela City University de Londres e doutora e livre-docente em psicologia social pela Universidade de São Paulo. É docente no Museu de Arte Contemporânea da USP desde 1990

Hal Foster é historiador, crítico e teórico da arte. Professor de Arte e Arqueologia na Universidade de Princeton.

\section{Crítica Literária, outras Artes e Mídias}


Luis Camilo Osório é doutor em Filosofia pela Pontifícia Universidade Católica do Rio de Janeiro, professor e curador do MAM-RJ, desde setembro de 2009.

Luiz Renato Martins é professor de história, teoria e crítica de arte no Departamento de Artes Plásticas da Escola de Comunicações e Artes da USP.

Marcelo Coelho é membro do Conselho Editorial do Jornal Folha de São Paulo e escreve semanalmente no caderno "Ilustrada", desde 1990. Formou-se em Ciências Sociais e é mestre em Sociologia pela USP.

Ricardo Basbaum é artista, escritor, crítico, curador, e professor do Instituto de Artes da Universidade do Estado do Rio de Janeiro.

Rodrigo Naves é crítico de arte, professor e escritor. Publicou diversas monografias sobre artistas plásticos, como Amílcar de Castro (1997), Nelson Félix (1998), Goeldi (1999) e Carlito Carvalhosa (2000), além de Forma difícil (1997), série de ensaios sobre arte brasileira.

Ronaldo Brito é professor no curso de especialização em História da Arte e Arquitetura no Brasil e do Programa de Pós-gradução em História Social da Cultura na PUC do Rio de Janeiro. No jornal Opinião, colaborou na seção cultural do primeiro ao último número (1977). No mesmo período foi um dos editores da revista Malasartes e do jornal A parte do fogo.

Teixeira Coelho é crítico de arte, professor titular de política cultural, coordenador do Observatório de Política Cultural, Escola de Comunicações e Artes (ECA-USP); diretor do Museu de Arte Contemporânea de São Paulo (MACUSP), de 1998 a 2002; colaborador de Bravo!, Folha de S. Paulo, Punto de Vista, TodaVia.

\section{REFERÊNCIAS}

1. Texto baseado na entrevista de Ronaldo Brito à Revista Lugares - Fundação Iberê Camargo, 30.06.2005. Disponível em: <http://www.iberecamargo.org.br/content/revista_nova/ entrevista integra.asp?id=125>. Acesso em: 18 de agosto de 2008.

2. Texto baseado na entrevista de Agnaldo Farias à Revista Lugares. Fundação Iberê Camargo, 28.10.2004. Disponível em: <http://www.iberecamargo.org.br/content/revista_nova/ entrevista_integra.asp?id=79>. Acesso em: 18 de agosto de 2008.

3. Texto baseado nos escritos de Cristina Freire, "Afasias na Crítica de Arte Contemporânea", em GONÇALVES, Lisbeth Rebollo; FABRIS, Annateresa (Org.) Os lugares da crítica de arte. São Paulo: Imprensa Oficial, 2005, p. 63-75.

\section{Crítica Literária, outras Artes e Mídias}


4. Texto baseado nos escritos de Arthur Danto, "Três décadas após o fim da arte", em DANTO, Arthur. Após o Fim da Arte: A Arte contemporânea e os Limites da História. São Paulo: A Arte contemporânea e
Odysseus, 2006, p. $24-43$.

5. Texto baseado nos escritos de Hal Foster. "Contra o pluralismo", em FOSTER, Hal. Recodificação: Arte, Espetáculo, Política Cultural. São Paulo: Casa editorial paulista, 1996, p. 33-55

6. Texto baseado na palestra de Teixeira Coelho, no contexto do Simpósio "Padrões aos Pedaços", em 2005. Disponível em: < http://forumpermanente.incubadora.fapesp. br/portal/. event_pres/simp_sem/pad-ped0/documentacao-f/conf02/ teixeira_coelho_integra>. Acesso em: 18 de agosto de 2008.

7. Texto baseado na entrevista de Agnaldo Farias à Revista Lugares. Fundação Iberê Camargo, 28.10.2004. Disponível em: <http://www.iberecamargo.org.br/content/revista_nova/ entrevista_integra.asp?id=79>. Acesso em: 18 de agosto de 2008 .

8. Texto baseado nos escritos de Hal Foster. "Introdução", em FOSTER, Hal. Recodificação: Arte, Espetáculo, Política Cultural. São Paulo: Casa editorial paulista, 1996, p. 17-27.

9. Texto baseado nos escritos de Annateresa Fabris, "E no Princípio foi Duchamp...", em GONÇALVES, Lisbeth Rebollo; FABRIS, Annateresa (Org.) Os lugares da crítica de arte. São Paulo: Imprensa Oficial, 2005, p. 77-95.

\section{Crítica Literária, outras Artes e Mídias}


17. Texto baseado nos escritos de Ronaldo Brito, "Análise do Circuito", em BRITO, Ronaldo. Experiência crítica. (Org.) Suely Lima. São Paulo: CosaḉNaify, 2005. p. 53-63.

18. Texto baseado nos escritos de Ronaldo Brito, "Análise do Circuito", em BRITO, Ronaldo. Experiência crítica. (Org.) Suely Lima. São Paulo: CosaçNaify, 2005. p. 53-63.

19. Texto baseado nos escritos de Ricardo Basbaum, "O artista como curador", em FERREIRA, Glória. Crítica de Arte no

Brasil: Temáticas Contemporâneas. Rio de Janeiro: Funarte, 2006. p. $235-240$. 